\title{
LAS COMISIONES DE LA VERDAD Y EL DERECHO A LA VERDAD DE LAS VÍCTIMAS EN LOS PROCESOS DE PAZ CON LAS AUTODEFENSAS UNIDAS DE COLOMBIA Y LAS FARC E.P.
}

\author{
THE TRUTH COMMISSIONS AND THE RIGHT TO THE TRUTH \\ OF VICTIMS IN THE PEACE PROCESSES WITH THE UNITED \\ SELF-DEFENSE OF COLOMBIA AND THE FARC E.P.
}

\section{CARLOS ALFONSO PADILLA SUÁREZ*}

\section{Resumen $^{1}$}

Colombia ha venido sufriendo los efectos de una guerra interna conocida como conflicto armado, sus causas obedecen a diferentes factores; sin embargo, lo que se abordará en esta oportunidad es cómo en el marco del conflicto se ve inmiscuido el derecho a la verdad, para denotar la evolución que ha tenido el concepto de verdad en el desarrollo de este proceso de guerra armada interna, ampliamente marcadas por graves crímenes de lesa humanidad, la verdad fue el desencadenante primario para investigar sobre esta problemática que, invita a la reflexión respecto de la importancia de la memoria en estos escenarios de conflicto, pues no hay claridad sobre

${ }^{*}$ Docente titular en la Facultad de Derecho de la Universidad Cooperativa de Colombia Sede Arauca, docente de Especialización en la Universidad Libre de Colombia - Bogotá. Presidente del Capítulo Arauca del Instituto Colombiano de Derecho Procesal, Conjuez del Tribunal Administrativo de Arauca. Email- carlospadillasuarez@hotmail.com carlos. padillas@campusucc.edu.co.

1 Este artículo se deriva de la investigación de "Las Comisiones De La Verdad Y El Derecho A La Verdad De Las Víctimas En Los Procesos De Paz Con Las Autodefensas Unidas De Colombia Y Las FARC E.P” realizada por el abogado, investigador y docente Carlos Alfonso Padilla Suárez de la Universidad Cooperativa de Colombia-Sede Arauca, en apoyado de los estudiantes como auxiliares de investigación Jairo Brito, Carol Begambre y Lizbeth Flores. 
los hechos ocurridos por parte de los grupos y el Estado, la verdad será revisada como un concepto además, de la verdad como medio de restaurar el contexto colombiano sometido a esta problemática de la guerra que dicta escenarios complicados de convivencia y la experiencia internacional vista desde el ámbito casuístico que se desarrollaran en este articulo

\title{
Palabras Clave
}

Derecho Internacional, Verdad, Tratados Internacionales.

\begin{abstract}
Colombian country has been suffering the effects of an internal war known as armed conflict, its causes are due to different factors, however, what will be addressed on this occasion is how the right to the truth is intruded in the context of the conflict, to to denote the evolution that the concept of truth has had in the development of this process of internal armed warfare, widely marked by serious crimes against humanity, the truth was the primary trigger to investigate this problem that invites reflection on the importance of the memory in these conflict scenarios, since there is no clarity about the events that have taken place by the groups and the State, the truth will be reviewed as a concept in addition to the truth as a means of restoring the Colombian context subjected to this problem of war that dictates complicated scenarios of coexistence and the international experience seen from the casuistic field that was developed will call in this article.
\end{abstract}

\section{Keywords}

International Law, Truth, International Treaties.

\section{INTRODUCCIÓN.}

La sociedad colombiana ha venido siendo expuesta a una multiplicidad de problemáticas que afectan su porvenir, los grupos armados al margen de la ley que se organizan afectan el orden constitucional, se revisa entonces en este proceso dos actores que en la actualidad tienen injerencia sobre el país; esta guerra ha tenido una duración de más de cincuenta (50) años. 
Las violaciones al Derecho Internacional Humanitario ha sido una constante en esta sociedad, manifestado en diversas formas degradantes del conflicto hacia las víctimas de este hecho, suelen quedar en medio de dos polos dispares que no logran satisfacer las exigencias mínimas de convivencia y respeto hacia la vida, la libertad, entre los muchos valores que carecen han dañado de manera considerable el tejido social colombiano, esta situación ha perjudicado los derechos de muchos ciudadanos colombianos que han sido objeto masacres, homicidios, torturas, tengan la posibilidad de ser reconocido como una forma de convivir con este difícil problema y como un hecho que efectivamente aconteció pues suelen ser omitidos por estos grupos o la ausencia del Estado en proteger el derecho a la verdad.

Esto nos lleva a analizar la memoria como un medio idóneo de salvaguardar la dignidad de las víctimas del conflicto, esta importancia ha sido resaltado por Gómez: "la memoria social, colectiva e histórica son relatos y narrativas, pero son relatos y narrativas que construyen subjetividad, identidades y realidades históricas, construyen"; ${ }^{2}$ en este sentido la memoria guarda relacion con la verdad pero está vista como un derecho, entonces se puede observar que la verdad es una expresión de la percepción personal y la visión de la sociedad que la compone, esto marca una manera de pensar, ese comportamiento hace parte del mecanismo humano, este derecho ha sido de gran importancia para el orden internaional al respecto tenemos: “(...) La verdad es un derecho inalienable que tiene toda persona y sociedad a conocer la realidad íntegra, completa y pública sobre los hechos ocurridos que rodearon las violaciones a los derechos humanos, sus circunstancias específicas, los motivos que las propiciaron y quienes participaron en ellas".

En Colombia la verdad puede ser vista como un pilar fundamental que podemos ubicar en dos dimensiones, en la primera es la esfera personal que involucra directamente a la victima y la dimension colectiva que afecta al Estado donde ocurre una vulneracion, al respecto Rojas desarrolla: "Se trata entonces de un derecho en evolución permanente, que reconoce como titulares a la víctima, su familia y la sociedad entera, por lo que se reconoce una doble dimensión, de derecho particular y derecho colectivo;

2 GÓMEZ, J. D.: "Por los caminos de la memoria. La construcción social de la identidad de la víctima". En: Kavilando, vol. 8, No1, 2016. pp. 29-42.

3 ORGANIZACIÓN DE LAS NACIONES UNIDAS: El relator especial Theo Van Boven, proyecto de principios y diectrices básicos sobre el Derecho de las victimas de Violaciones Graves de los Derechos Humanos y el Derecho Internacional Humanitario a Obtener Reparación. 2016 (Consulta: 11 de 09 de 2019). 
es un derecho que obliga al Estado a efectuar las acciones necesarias para alcanzarla; le impide obstaculizar su obtención, ya sea por vías directas como indirectas; obliga al Estado a una actitud positiva para eliminar cualquier barrera legal que dificulte su obtención, constituyendo, de este modo, una garantía en la prevención futura de nuevos abusos. De esta forma, podemos señalar que es parte idónea y esencial dentro de los procesos de reparación para los afectados". ${ }^{4}$

Incluso en la experiencia internacional se puede entrever el desarrollo de este derecho que es visto como autónomo y esencial para construir una sociedad, es por eso que en esta ocasión se pasará a vigilar la experiencia propia en dos grupos que han marcado de manera signfiicativa la historia nacional, no solo por su duración, si no por la crudeza del conflicto pues la degradacion de la víctima es habitual en este escenario, la historia del por qué surgieron estas situaciones no son claras por parte del Estado, por ello es esencial conocer ¿cuáles son los parámetros del derecho a la verdad en los procesos de paz con las FARC Y AUC?, esto, para poder lograr constrastar las normas y y procesos que permitan conocer la realidad del derecho a la verdad en el contexto colombiano, para, finalmente, dar una breve conclusión del proyecto de investigación citado.

\section{MATERIALES Y MÉTODO.}

El desarrollo de este artículo incorpora una metodología en la que se involucran fuentes primarias, secundarias, que permiten el desarrollo de un modelo cualitativo que parte de la interpretación de las disposiciones normativas vigentes y aplicables a la problemática que es objeto de estudio, esto es, fijar ¿cuáles son los parámetros del derecho a la verdad en los procesos de paz?, situado, por una parte, en el marco del proceso de negociación con las autodefensas Unidas de Colombia y por la otra, el estudio de la comisión para el esclarecimiento de la verdad en el proceso de paz con las fuerzas armadas revolucionarias de Colombia. Para el logro de este propósito, se aplicará el método analítico para establecer un análisis comparativo de regulación y el alcance de las comisiones de la paz en el proceso de las AUC y de las FARC E.P. Luego, se señalan cuáles han sido las garantías otorgadas a la reparación de las víctimas como consecuencia de los informes de las comisiones de la verdad, es decir, se parte de un

4 BERNALES ROJAS, G.: "El derecho a la verdad". En: Estudios Constitucionales, vol.14, N², 2016. 
método hermenéutico que involucra las disposiciones establecidas por el legislador ordinario y extraordinario.

\section{RESULTADOS.}

Considero necesario acercarnos al significado del derecho a la verdad, destacando el trabajo de Restrepo, el cual define: "El concepto de verdad, recuperado gracias a la etimología (a-letheia: des ocultación, desvelamiento), permite concebir realmente el modo de manifestación del ser (...) El término griego $\alpha \lambda \eta / \theta \varepsilon 1 \alpha$ está constituido por el prefijo a, que posee el sentido de negación o carencia de algo; y por la raíz lhq, que posee el sentido de estar oculto u olvidado". 5

La definición anterior compagina con la problemática de violencia interna en Colombia pues al no conocer la veracidad ni la totalidad de los hechos ocurridos se vulnera ampliamente este derecho; la importancia de este derecho es desarrollada en el derecho internacional principalmente donde es atribuido su origen, en adelante se revisarán los antecedentes judiciales desarrollado en el derecho internacional, para poder determianar cuál es la funcion de la verdad como derecho.

A través de diferentes casos se violaron derechos fundamentales en ocasión de un conflicto armado interno o régimen dictatorial, que generó víctimas directas e indirectas, implicaron procesos judiciales para conocer los hechos que incentivaron y aquellos que fueron sancionados, principalmente, en cabeza de los estados; este primer historial se puede fijar en el protocolo 1 de los convenios de Ginebra $1949^{6}$, artículo 32 que establece " el derecho que asiste a las familias de conocer la suerte de sus miembros", pero la configuración de este derechos se empieza a articular desde la Corte Interamericana de los Derechos Humanos con el informe presentado que vincula a los Estados con la obligación de investigar, sancionar, las violaciones en casos de tortura, ejecuciones extrajudiciales y desapariciones forzadas con el ánimo de conocer lo ocurrido; esto fue coadyuvado por el comité de derechos humanos órgano de control del pacto internacional de los derechos civiles y políticos en 1983 (Corte

5 RESTREPO, J.A.: "La etimología de verdad y la verdad de la etimología". En: Foro de Educación, vol. 3, №5-6, 2005. pp. 110-118.

6 PINTO, M.: L'Amerique latine et le traitement des violations massives des droits de l'homme. Pedone, ParÍs., en GONZÁLEZ-SALZBERG, D. A.: "El derecho a la verdad en situaciones de post-conflicto bélico de carácter no-internacional.” En: International Law: Revista Colombiana de Derecho Internacional, 2008. pp. 435-467. 
Interamericana de Derechos Humanos, 1976) ${ }^{7}$, reiteró la obligación de investigar lo acontecido en relación con el estado y los casos de desaparición forzada; otro antecedente que cabe mencionar es el del año 1985-1986 (Corte Interamericana de Derechos Humanos, 1986) ${ }^{8}$, se posiciona como el primer organismo que reconoce la existencia de la verdad como derecho, le otorga un carácter de irrenunciable tanto para los familiares de las víctimas, como para la sociedad en su conjunto, de conocer la realidad de los casos ocurridos que atentan contra el derecho a la verdad.

Así las cosas, acorde con la experiencia que ha tenido la Corte Interamericana de los Derechos Humanos, se deja de presente el primer litigio en (Caso Vélazques Rodríguez, 1988) hace un tímido reconocimiento del derecho a la verdad, pues en el caso en cuestión, la Corte reconoció el derecho de los familiares a conocer el paradero de un estudiante víctima de desaparición forzada, se podría hablar del antecedente que marcó la dimensión colectiva del derecho a la verdad, ya que al fijar el derecho a la verdad, no solo lo relaciona con la victima directa, sino que también está en sus familiares como victimas indirectas, además de que el alto tribunal, en la sentencia indemnizatoria, fijó la obligación de los Estados que aceptaron el convenio del sistema interamericano, por tanto, es deber acatar el artículo 1.1 de esta Convención, que nos habla de la obligación de investigar seriamente las violaciones ocurridas, con el ánimo de juzgar e imponer las sanciones pertinentes, es a raíz de este hecho que, la $\mathrm{CIDH}$ hizo énfasis en los casos de graves violaciones de derechos humanos, como las ejecuciones extrajudiciales, tortura y desaparición, esto se puede ver en litigios como: Caballero,Delgado y Santana, 1995; Caso Blake, 1998; Durand y Ugarte, 2000; Niños de la Calle, 2001; Bámaca Velásques, 2002; Hermanos Paquiyauri, 2004; Xtemenes Lopes, 2006. El reconocimiento de este derecho se ha desarrollado paulatinamente, pues en un principio la CIDH estableció la sentencia como medio de reparación, debido a la función que cumple con un triple objetivo: la satisfacción moral de las víctimas y sus familiares; el fortalecimiento de la cultura social de la legalidad; como también, el servicio a la verdad en bien de los agraviados y de la sociedad en su conjunto.

De este modo, se reconoce la importancia del derecho a la verdad, además de incluir otros medios de reparación simbólica a través de homenajes, monumentos, publicaciones, usar nombres de víctimas en las

$7 \quad$ Ibídem.

8 Ibídem. 
escuelas destinados a salvaguardar la memoria de la tragedia ocurrida; esto permite satisfacer colectivamente el derecho a la verdad en aras de fomentar la no repetición del hecho victimizante y sanar el tejido social dañado por el conflicto usando como medio la memoria, pues esta permite llevar un proceso de duelo al dignificar la víctima y repudiar estas acciones para que no vuelvan a suceder

Hay que mencionar, la experiencia internacional del caso Mexicano Radilla Pacheco vs Estados Unidos , 2009, pues la CIDH exhorta al Estado mexicano a conocer los patrones sistemáticos que permitan identificar las razones del por qué se perpetró la desaparición forzada al caso citado, esto se debe a que no hay certeza frente a los hechos ocurridos pues la fuerza pública y el crimen organizado se unieron para la comisión del delito, impidiendo que la investigación siguiera su curso, dilatándola e impidiendo que se conozca la verdad de lo acontecido, se denota la complejidad del caso pues el Estado, en esta ocasión, no es garante de los derechos humanos y dificulta el acceso al derecho a la verdad, existe la necesidad notada por la Corte como guardián de los derechos del hombre de ampararlo; la ausencia de investigaciones en los casos de graves violaciones a los derechos humanos no permiten que se satisfagan los supuestos mínimos para que se configure plenamente el derecho a la verdad, son una constante en los pueblos latinoamericanos, las desapariciones forzadas, ejecuciones extrajudiciales.

Toda afectación a la vida y el derecho a la verdad violan disposiciones como: ONU: Asamblea General, 1948; la Declaración Universal de los Derechos Humanos, arts. 3, 5, 8,9 y 10 referentes al derecho a la vida, libertad, seguridad personal, derecho a la verdad e información, es un problema que afecta profundamente la democracia y legitimidad de las instituciones del Estado conforme al pronunciamiento de la CIDH en el informe denominado "derecho a la verdad en las américas "resalta la necesidad que tiene Las sociedades en preservar este precepto, así lo ha reconocido tanto en la Declaración Americana de Derechos Humanos como en la Convención, artículos XVIII y XXIV de la Declaración Americana, artículos 8 y 25 de la Convención Americana.

De otra parte, se estableció que el derecho a la verdad guarda relación con el derecho de acceso a la información, contemplado en el artículo IV de la Declaración Americana y el artículo 13 de la Convención 
Americana (CIDH, 2014) ${ }^{9}$, en el caso colombiano encontramos el fallo de los desaparecidos del Palacio de Justicia el cual aporta a la evolución del sistema interamericano de derechos humanos, pues reconoce a la verdad como base de otros derechos en conexidad, ya que el violar estos presupuestos implica que no se lograría la justicia ni la reparación, que son los fines que busca proteger este derecho, sobre todo en un país como Colombia que se encuentra en el marco de un conflicto armado latente, valga citar que el no satisfacer este derecho incurriría en una forma de trato cruel e inhumano para los familiares cercanos, que afecta su integridad personal y su derecho a conocer la verdad, un ejemplo de ello es lo acontecido en iguala-México, donde las investigaciones son un medio para establecer la verdad jurídica, además de que mediante esta acción se logra consumar la satisfacción del derecho a la justicia y la verdad de las víctimas, que estimula la superación de estos hechos pues suscita tranquilidad con la premisa de que los hechos fueron sancionados, al respetar las garantías internacionales y legales teniendo como norte proteger a las víctimas de conductas violatorias del $\mathrm{DIH}^{10}$.

Por otra parte, el derecho a la verdad ha sido de vital importancia para la sociedad colombiana, pues debido al conflicto armado se han vulnerado los derechos humanos de manera sistemática, lo que desencadenó una serie de mecánicas sociales que produjeron miles de víctimas, es por eso que se desarrollan procesos de paz donde su óptica se encuentra en proteger a las víctimas, para de esta manera poder compensar la necesidad de conocer los hechos ocurridos, pues en muchas ocasiones los grupos al margen de la ley, esconden los cuerpos, desaparecen los familiares, y les niegan el proceso de luto, asunto que es fundamental para poder continuar con el diario vivir de los afectados por el conflicto, no solo a los perpetradores, o las víctimas, sino también a sus familiares que se vieron seriamente comprometidos a raíz de este atolladero en el que el Estado no ha podido cumplir con la obligación de proteger, sancionar, juzgar al punto de que necesita cambiar la forma en que administra justicia por medio de la justicia transicional, pues no tiene la capacidad para identificar todos los casos de barbarie ocurridos, es por ello que en esta investigación se analizarán los procesos de justicia transicional, ley justicia y paz (AUC), y el acuerdo de La Habana (FARC

9 GÓMEZ, V. G. (2015). Derecho a la verdad: estudiantes desaparecidos en Ayotzinapa. México. p. 107-119. Consulta: 11 de 11 de 2019

10 Ibídem. 
EP), con la intención de conocer si el derecho a la verdad fue protegido en estos procesos.

\section{Función del derecho a la verdad.}

Es evidente, que este derecho nace de la precariedad de condiciones de vida que se presentan en un territorio, se vincula al derecho de las víctimas a conocer la coyuntura que los hechos que lesionaron sus derecho a vivir en paz, pero aparte de su derecho a reconstruir su vida, es por ello que la verdad necesita ser revelada, para que las autoridades construyan una versión oficial del por qué sucedieron estas conductas, ya que al permitirle a los habitantes la socialización de estos hechos, hace tránsito a la reparación social que permita recrear la sociedad antes de presentarse la divergencia, esto fomenta a que se recupere la confianza en las instituciones del Estado para restaurar aquellos grupos sociales que han sido vulneradas por el conflicto; de esta manera se puede observar la esencia colectiva que presenta el derecho a la verdad como piedra angular de la creación de una sociedad equitativa, que respeta los fines esenciales del estado y permite su pacífica convivencia. ${ }^{11}$

Según este orden de ideas, se establece cuál es la función que tiene el derecho a la verdad y su importancia en contextos de conflicto, pero el alcance del derecho de la verdad tiene relación con otros aspectos inherentes al desarrollo del hombre en sociedad, tal es el caso, que se puede establecer una relación simbiótica en cuanto a la garantía de administración de justicia, el acceso que se tiene a las reparaciones que tiene lugar, además de la instauración de políticas públicas, instituciones que tengan en cuenta la calidad especial de víctima, y propenda por manifestar sus inquietudes y convivir con su duelo, de la mano de los esfuerzos gubernamentales para preservar la memoria histórica de lo acontecido, en el territorio, de esta manera se identifica la plural funcionalidad que presenta preservar y pronunciarse frente a los actos que modificaron la estructura social de las poblaciones afectadas por el flagelo de la guerra pues el desconocer estas garantías implicaría desconocer la existencia de un ser humano, obra que va en contra de la esencia del Estado Social de Derecho, pues si se permite que particulares decidan sobre la vida de los ciudadanos se perdería el sentido por

11 UPRIMNY, R. y SAFFON: "Derecho a la verdad alcances y limites de la verdad judicial". EN: . Bogotá, 2006. SUMALLA, J. M.: "Comisiones de la verdad y justicia penal en contextos de transición." En: DE GAMBOA, Camila (ed.) aIndret: Revista para el Análisis del Derecho, Nº1, 2010. pp. 1-29. 
el cual se forjó el Estado, como por arte de magia sin tener una razón clara del por qué sufrieron estas consecuencias sin haber dañado a nadie, situación que no es nueva en nuestro ordenamiento pues desde múltiples lugares es un común denominador esté tipo de conductas reprochables, esta condición hace apología a lo dicho por el nobel colombiano que tiene vigencia aun después de pasar muchos años luego de su publicación : "En la noche, después del toque de queda, derribaban puertas a culatazos, sacaban a los sospechosos de sus camas y se los llevaban a un viaje sin regreso. Era todavía la búsqueda y el exterminio de los malhechores, asesinos, incendiarios y revoltosos del Decreto Número Cuatro, pero los militares lo negaban a los propios parientes de sus víctimas, que desbordaban la oficina de los comandantes en busca de noticias. 'Seguro que fue un sueño', insistían los oficiales. 'En Macondo no ha pasado nada, ni está pasando ni pasará nunca. Este es un pueblo feliz'. Así consumaron el exterminio de los jefes sindicales."12

A partir del texto anterior, resulta evidente que en Colombia ha existido desde hace mucho tiempo una cultura del olvido, que ha permitido las injusticias y la violación flagrante de la dignidad de los colombianos, la verdad se posiciona como el paso hacia una transformación social que suscite la transparencia en el actuar de las instituciones, que investigue, documente y socialice de manera adecuada a la sociedad para que se logre transformar el tejido social colectivo, o en palabras de V. Bueno, ${ }^{13}$ "Su caracterización como "derecho colectivo" debe ser entendida como un modo de señalar que la instauración de una "cultura de la verdad" es un elemento imprescindible de la transición de un régimen autoritario a una sociedad democrática", este proceso de empoderamiento debe ser propiciado por las Autoridades y las diversas organizaciones que tienen responsabilidad de difundir trabajos investigativos, culturales, sociales, económicos, dignificando a las víctimas y fortaleciendo la sociedad en general.

\section{Parámetros del derecho a la verdad en Colombia.}

En primera medida, es imprescindible analizar cómo en los procesos de paz se ha desarrollado el derecho a la verdad, así las cosas, se empieza con dos leyes principales; la primera conocida como Ley de Justicia y Paz

12 MÁRQUEZ, G. G. (1967). Cien años de Soledad. Buenos Aires: Plaza y Janes S.A.

13 SUMALLA, J.T.: "Comisiones de la verdad y justicia penal en contextos de transición". En: INDRET, Barcelona, 2010. 
(Congreso de la República, 2005); que fue reglamentada posteriormente vía decreto (Congreso de la República, 2005) propuesta por el Gobierno de Álvaro Uribe Vélez, donde desarrolla aspectos que cobijan al derecho de verdad y su relación sustancial con los procesos derivados del proceso de paz denominada como "ley de justicia y paz". Valga resaltar que esta disposición es el primer antecedente de justicia transicional en Colombia, se atiende a mencionar todos aquellos párrafos orientados a satisfacer el derecho a la verdad en las victimas, dentro de este propósito inicia según el Artículo 7 establece: "La sociedad, y en especial las víctimas, tienen el derecho inalienable, pleno y efectivo de conocer la verdad sobre los delitos cometidos por grupos armados organizados al margen de la ley, y sobre el paradero de las víctimas de secuestro y desaparición forzada. Las investigaciones y procesos judiciales a los que se aplique la presente ley deben promover la investigación de lo sucedido a las víctimas de esas conductas e informar a sus familiares lo pertinente. Los procesos judiciales que se adelanten a partir de la vigencia de la presente ley no impedirán que en el futuro puedan aplicarse otros mecanismos no judiciales de reconstrucción de la verdad".

Conforme lo señalado, en justicia y paz se generan una serie de obligaciones y responsabilidades por parte del Estado, como hacia los actores inmersos del conflicto, catalogan a la verdad como un derecho inalienable, se erige la necesidad de satisfacer el derecho a la verdad al tomar como deber de los insurgentes brindar información que permita conocer sobre los hechos cometidos, los familiares están inmiscuidos en esta fórmula pues debe informárseles, también, sobre el paradero de sus víctimas; otro aspecto importante es que no cierran la línea de reparación a un solo rasgo, pues según el caso se pueden aplicar diferentes métodos que no sean solo de carácter judicial para poder reconstruir esta verdad lesionada por el conflicto.

Según el orden propuesto, el art 15 expresa que la función del esclarecimiento de la verdad igualmente pertenece a los servidores públicos, que les fue asignada la labor de recopilar los hechos más importantes con relación a la verdad de las víctimas, derivadas de los grupos paramilitares encaminados a sustentar un relato que describía las circunstancias de modo, tiempo y lugar por medio de la Unidad Nacional de Fiscalía para la Justicia y la Paz, la cual le asiste la función de informar a los familiares de los resultados obtenidos a través de la investigación, delimitar la magnitud del daño causado, así como proteger a los testigos, peritos, víctimas que 
puedan ser vulnerados en ocasión de un juicio. Por otra parte, el artículo establece que se deberá velar por la protección de los Magistrados que conozcan de casos de este talante por parte del Consejo Superior de la Judicatura, la defensa legal será realizada por la Defensoría del Pueblo, este artículo moldea a los involucrados como un todo para perseguir el fin que es esclarecer la realidad de lo ocurrido.

De otra parte, en el ámbito procesal, el art 17 de la misma ley regla los pasos que se deben seguir para lograr la verdad y el esclarecimiento de los hechos, este aparte llama a los desmovilizados a ofrecer versión libre ante el fiscal delegado en su caso, donde relatarán los hechos conocidos para aportar a construir la verdad, también establece la posibilidad de incluir bienes que se hayan obtenido ilícitamente para reparar el daño causado a las víctimas, la Fiscalía deberá relacionar el programa metodológico para iniciar la investigación además de verificar los datos suministrados donde será llevado a rendir audiencia de imputación en las 36 horas siguientes.

Continuaremos la exploración del tema, en el artículo 29 que instituye la responsabilidad que tienen los relatos brindados por los desmovilizados, pues en caso que los datos suministrados resulten falsos, inocuos y no lleven a ningún resultado, esto ocasionaría la ruptura del beneficio de la pena alternativa, de manera que se estableció como premisa que lo narrado por los desmovilizados, tengan la condición de verdad, de lo contrario será juzgado conforme a la justicia ordinaria.

Sumado a lo anterior, el capítulo octavo señala el derecho a las víctimas frente a la administración de justicia que compone una variedad de garantías encaminados a brindarle seguridad a la víctima, su enfoque debe ser sin el menoscabo de la dignidad de la misma, sin distinción de edad, género, ni la naturaleza del delito que se investiga; el Estado se encargará de proteger su seguridad y la de sus familiares, deberá ofrecer reparación por los daños causados sujetos a las garantías procedimentales establecidas, conocer la verdad de los hechos, brindar la oportunidad de interponer recursos frente a una fallo judicial, como a ser informados de la decisión tomada. Tendrán derecho a ser orientados por un abogado con el que tengan familiaridad para llevar su caso según lo consideren, el gobierno le corresponderá otorgar asistencia integral que permitan la restauración de sus derechos, en el caso de que no se pueda hacer entender se le brindara un traductor que permita dar a conocer su sentir.

Más aun, prosigue el trabajo de los funcionarios en advertir medidas tendientes a salvaguardar la entereza física, psicológica, es 
decir, ofrecer bienestar en todo lo que compone la persona dañada por el conflicto, se capacitará de manera especial a los funcionarios que conocen de estos asuntos, la víctima tendrá derecho a llevar audiencia cerrada en caso de que se perjudique su integridad, se realice la recepción del testimonio por medio de audio video, cuando sean juicios de delicada situación tal es el caso de niños, niñas o adolescentes análogos con el conflicto sin poner en peligro la humanidad de la víctima por recolectar alguna prueba.

Consecuentemente, el capítulo noveno habla sobre las medidas de reparación a las víctimas que nacen de los favorecidos por esta ley que deberá retribuir el daño realizado; en cuanto la solicitud de reparación, la víctima tendrá la potestad de ser iniciada en forma directa o de comprobarse un nexo causal ocasionado por las AUC, podrá el fiscal de la unidad, el tribunal, ordenar la reparación por medio del fondo de reparación, dicha reparación se hará en base a la restitución, indemnización, rehabilitación y satisfacción; según el capítulo se entiende como reparación integral la entrega de bienes obtenidos de manera ilícita, declaraciones públicas que fomenten la dignidad de la víctima y demás afectados, manifestar que se arrepienten de haber causado las lesiones en evento público junto a la promesa de no repetir tales actos, ayudar a ubicar desaparecidos, cuerpos de fallecidos a raíz de esta problemática, para que las víctimas puedan cerrar el ciclo de dolor según sus costumbres y guarden luto a los fallecidos.

Algo más que añadir, es lo que considera esta ley como restitución pues, en resumen comprende todas aquellas acciones encaminadas a volver a la víctima al estado natural antes de ser afectada por el hecho victimizante, por ejemplo, devolver a la persona a su lugar de origen, sus propiedades, su libertad en caso de que así se necesite; en cuanto a la rehabilitación debe ser dirigida a las víctimas o sus familiares en primer grado de consanguinidad mediante atención médica, psicológica, servicios sociales que otorgue la administración, becas de estudio, bonos, todo aquello que pueda recuperar su dignidad individualmente o en sociedad. Las medidas de satisfacción y garantías de no repetición empiezan desde el reconocimiento de la verdad judicial, corroborar los hechos, difundirlos a la opinión publica siempre y cuando no represente un peligro para la víctima y de esa forma evitar la revictimización, aplicar sanciones a los responsables de la conducta violatoria de derechos humanos. Recordar a través de homenajes, conmemoraciones, para que se reconozca a las 
víctimas a manos de los grupos insurgentes, si se considera necesario, podrá condenarse a los responsables a asistir a capacitaciones, cursos que traten sobre Derechos Humanos y tendrán derecho las víctimas a la atención estatal en todos los niveles que permitan recuperar la confianza en el Estado social de Derecho, al promover, dignificar la importancia de los Derechos Humanos, las victimas en el territorio afectado a nivel particular y general en Colombia.

Para estos efectos, se crea la Comisión Nacional de Reparación y Reconciliación que deberá hacer un minucioso análisis de las conductas evidenciadas, como de un exhaustivo seguimiento con una duración de 8 años para verificar que se cumplan todas aquellas medidas que se mencionaron con antelación, con el ánimo de fomentar que la reconstrucción social sea una realidad más allá de las formas. Para lograrlo se vigilaría por la desmovilización veraz de los miembros para que no se tomen las armas nuevamente, pues de ocasionarse esto se continuaría el ciclo de la guerra; el acompañamiento será integral, por ello se crean las Comisiones Regionales para la Restitución de Bienes como medida de satisfacción, sin olvidar lo importante de la creación del Fondo para la Reparación de las víctimas a cargo del director de la Red de Solidaridad Social que deberá agilizar el pago correspondiente; además de, si se creyese preciso concebir otras medidas de reparación, podrán ser ordenadas por esta institución que está sujeto a revisión por parte de la Contraloría General como soporte adicional que justifique su cumplimiento.

Aquí he de referirme también al capítulo once, ya que resulta un aparte especial pues consagra a la memoria como un deber del Estado en preservar la verdad de lo acontecido dentro del marco de la guerra interna con el paramilitarismo, sus causas y consecuencias, para ello se dispone a las entidades del Estado a preservar y obrar en rectitud de plasmar de manera fidedigna lo ocurrido, al consagrar el deber de proteger la información que tiene estrecha conexidad con el derecho a la verdad además, que opera como una medida de satisfacción individual, colectiva donde se deberá facilitar el acceso a esta información a todos los ciudadanos colombianos y a la víctimas cuando lo necesiten, sin perjudicar el derecho a la intimidad en casos delicados como violaciones, al tratarse de menores de edad, casos difíciles de publicar debido a su especie delictuosa para evitar que termine siendo re victimizado.

En lo que concierne a los parámetros establecidos en justicia y paz, se observa entonces una amplia gama de garantías que tienen como 
protagonista a las víctimas en toda la dimensión que le integra, de manera uniforme, donde involucra a todas las partes presentes en el conflicto sin que al momento de publicar los hechos se menoscaben las garantía de las víctimas, respeto por el procedimiento y sus principios; se identifican diversas formas sustanciales de sintetizar las reparaciones, beneficios por contar la verdad que de otro modo hubiera sido difícil recolectar información, todo ello encaminado a obtener una perspectiva del por qué se generó dicho conflicto, para que al estudiar sus causas, no se repitan los patrones sistemáticos que le dieron vida al conflicto armado interno, caso auto defensas unidas de Colombia, esto culmina en edificar el puente que hará tránsito hacia una sociedad respetuosa de la vida, la integridad y la dignidad de los pobladores que componen al país desde sus células más pequeñas, hasta sus complejos entretejidos sociales reducidos por la guerra

Por último, se citará el balance diagnosticado por esta ley en relación a los casos de violencia derivados de este grupo armado, (Tabla 1) estos datos fueron evidenciados por Córdoba (,2018, págs. 13,14).

\section{Caso FARC:}

El 31 de julio de 2012 se aprobó reforma Constitucional, la cual aplico el Marco Jurídico para la Paz. A través de esta nueva normatividad, se reformó la Constitución, arts. 66 y 67, para dar tránsito hacia la aplicación de las diferentes medidas judiciales y extra- judiciales que permitieron la materialización de estos mecanismos, como es el caso de la Comisión de la Verdad que gracias a este artículo surgió a la vida jurídica. La premisa en que se forjó esta reforma fue la de verdad, justicia, reparación y garantías de no repetición para esclarecer hechos generados a raíz del conflicto, dicha disposición fue sujeta a control por parte de la Corte Constitucional, 2013, que abordó este marco declarando la exequibilidad de la reforma jurídica otorgándole su visto bueno en cuanto a que se adecua a los derechos de las víctimas. 
Tabla 1 Balance del proceso de desmovilización y reinserción de los paramilitares

\begin{tabular}{|l|c|}
\hline DESCRIPCIÓN & TOTAL \\
\hline Total de hechos imputados (Ley 975 de 2005) & 82.563 \\
\hline Número de víctimas en hechos imputados (Ley 975 de 2005) & 211.013 \\
\hline Número de postulados (Ley 975 de 2005) & 1.399 \\
\hline Número de Sentencias proferidas en Justicia Transicional & 55 \\
\hline Jornadas de atención a víctimas (Ley 975 de 2005) & 906 \\
\hline Total de víctimas atendidas en jornadas (Ley 975 de 2005) & 169.992 \\
\hline $\begin{array}{l}\text { Total de bienes respecto de los cuales se adelanta proceso en } \\
\text { Justicia Transicional }\end{array}$ & 4.791 \\
\hline $\begin{array}{l}\text { Total del precio de los bienes con situación definida y pendientes } \\
\text { por entregar al FRV }\end{array}$ & $\$ 882.982 .362 .250,00$ \\
\hline Total de cadáveres exhumados & 8.736 \\
\hline
\end{tabular}

\begin{tabular}{|c|c|}
\hline Total de cadáveres en laboratorio con posible identidad & 1.861 \\
\hline Cadáveres en condición de no identificados en laboratorio & 2.574 \\
\hline Cadáveres entregados GRUBE Dirección de Justicia Transicional & 4.062 \\
\hline Situaciones juridicas resueltas (ley 1424 de 2010) & 21.086 \\
\hline $\begin{array}{l}\text { Formulación de cargos para sentencia anticipada (ley } 1424 \text { de } \\
2010 \text { ) }\end{array}$ & 17.942 \\
\hline Sentencias condenatorias (ley 1424 de 2010) & 8.116 \\
\hline Procesos activos de ley 1424 en la Dirección a corte 30 de junio & 5.431 \\
\hline $\begin{array}{l}\text { Investigaciones grupo compulsa de copias e investigaciones de } \\
\text { postulados excluidos }\end{array}$ & 457 \\
\hline
\end{tabular}

Fuente-(Fiscalía General De la Nación, 2017) 
Para resolver el problema planteado, se instauró derecho de petición radicado el día 18 de noviembre del 2019, dirigido hacia la Comisión de la Verdad, seccional Arauca- Arauca, en el cual se formularon las siguientes peticiones:

1. Se dé información sobre las medidas actuales que están tomando para garantizar la verdad

2. La información del estado actual del derecho a la verdad, ¿cuántas víctimas han podido ejercer su derecho y si ya se han encontrado a los responsables directos dentro del conflicto armado? A nivel nacional y en el departamento de Arauca.

En respuesta recibida vía correo electrónico el día 3 de diciembre de 2019 se suministró información de vital importancia, es por ello que se procederá a citar la respuesta desarrollada por esta institución que cuenta con el siguiente radicado 14101022019016862 Id: 19908; pues de manera clara y sencilla describe los parámetros esenciales tomados en el proceso de paz con las FARC EP, así como la labor que viene desarrollando actualmente, de lo cual se debe tomar en cuenta que la Comisión de la Verdad aún no ha terminado su mandato de 3 años, es así como se observa: El punto 5 del acuerdo, que nos refiere todo lo relacionado con las víctimas del conflicto armado, nos presenta la creación del Sistema integral de Verdad, Justicia, Reparación y no Repetición en adelante (SIVJRNR) compuesto por diferentes mecanismos judiciales y extra judiciales que se han puesto en marcha de manera coordinada con el fin de lograr la mayor satisfacción posible de los derechos de las víctimas, asegurar la rendición de cuentas por lo ocurrido, garantizar la seguridad jurídica de quienes participen en el Sistema Integral y contribuir a garantizar la convivencia, la reconciliación y la no repetición del conflicto y así asegurar la transición del conflicto armado a la paz El SIVJRNR está compuesto por la Comisión para el Esclarecimiento de la Verdad, la Convivencia y la No Repetición; la Unidad para la Búsqueda de Personas dadas por Desaparecidas en el contexto y en razón del conflicto armado; la Jurisdicción Especial para la Paz; y las medidas de reparación integral. Estos componentes del SIVJRNR operan de manera coordinada y articulada.

El Sistema es integral, en tanto no se trata de una serie de mecanismos aislados, sino de un conjunto de mecanismos interconectados de manera coherente, que están interconectados, entre otros, a través de relaciones de condicionalidad y de incentivos para acceder y mantener cualquier tratamiento especial de justicia. El Sistema Integral busca satisfacer, a 
través de los distintos mecanismos, los derechos de todas las víctimas del conflicto armado: víctimas de agentes del Estado, víctimas de las guerrillas, $\mathrm{y}$ también víctimas de los grupos paramilitares, que han encontrado respuesta en el marco de los procesos de justicia y paz y que pueden también participar en las medidas y mecanismos de verdad y reparación del Sistema. Para tal efecto los distintos mecanismos del Sistema buscan incentivar la colaboración de quienes tuvieron una participación directa o indirecta en el conflicto armado y cometieron delitos en el contexto y en razón de éste. Además de disponer de las medidas y mecanismos antes mencionados de carácter judicial y extrajudicial, es necesario establecer unos incentivos y condiciones para asegurar la contribución, a través de los mecanismos del Sistema Integral, a la satisfacción de los derechos de las víctimas por parte de quienes hayan cometido graves violaciones a los derechos humanos o graves infracciones al Derecho Internacional Humanitario

En cuanto a la Comisión para el esclarecimiento de la Verdad, la Convivencia y la No Repetición, fue creada mediante el Acto Legislativo 01 de 2017 y el Decreto 588 de 2017, como un mecanismo de carácter temporal (3 años) y extra -judicial del Sistema Integral de Verdad, Justicia, Reparación y No Repetición - SIVJRNR, estos mecanismos históricamente en procesos de transición (de dictaduras a la democracia y de conflictos armados a la paz) para esclarecer patrones de violencia. No es un mecanismo para administrar justicia, sino para contribuir a la verdad y reconocer los derechos de las víctimas. La principal fuente de información son los testimonios de las víctimas, aunque en muchos casos también acuden quienes tuvieron responsabilidad. La Comisión es una entidad de Estado que busca el esclarecimiento de los patrones y causas explicativas del conflicto armado interno (no abordará casos individuales), que satisfaga el derecho de las víctimas y de la sociedad a la verdad, promueva el reconocimiento de lo sucedido, la convivencia en los territorios y contribuya a sentar las bases para la no repetición, mediante un proceso de participación amplio y plural para la construcción de una paz estable y duradera La Comisión, de conformidad con lo establecido en el Decreto 588 de 2017, artículo 2o, deberá cumplir con los siguientes objetivos:

- Contribuir al esclarecimiento de lo ocurrido, de acuerdo con los elementos del mandato y ofrecer una explicación amplia de la complejidad del conflicto armado, de tal forma que se promueva un entendimiento compartido en la sociedad, en especial de los aspectos menos conocidos del 
conflicto, como el impacto del conflicto en los niños, niñas y adolescentes y la violencia basada en género, entre otros.

- Promover y contribuir al reconocimiento. Eso significa el reconocimiento de las víctimas como ciudadanos y ciudadanas que vieron sus derechos vulnerados y como sujetos políticos de importancia para la transformación del país; el reconocimiento voluntario de responsabilidades individuales y colectivas por parte de todos quienes de manera directa o indirecta participaron en el conflicto como una contribución a la verdad, a la justicia, a la reparación y a la no repetición; y en general el reconocimiento por parte de toda la sociedad de ese legado de violaciones e infracciones como algo que merece el rechazo de todos y que no se debe ni se puede repetir

- Promover la convivencia en los territorios, en el entendido de que la convivencia no consiste en el simple compartir de un mismo espacio social y político, sino en la creación de un ambiente transformador que permita la resolución pacífica de los conflictos y la construcción de la más amplia cultura de respeto y tolerancia en democracia. Estos tres objetivos deberán contribuir a crear las condiciones estructurales para la convivencia de todos los colombianos y sentar las bases de la no repetición, la reconciliación y la paz estable y duradera

En el marco de estos tres objetivos la comisión está desarrollando las actuaciones tendientes a garantizar la verdad, garantizando una estructura misional que pueda dar respuesta a estos objetivos, de la entidad encontramos:

Dirección de Conocimiento: encargada de la recolección y procesamiento de la información para la realización del informe final, además de coordinar con las territoriales la construcción de las rutas de investigación, bajo 10 núcleos temáticos:

○ Democracia y conflicto armado.

○ Papel del Estado y sus responsabilidades

- Modelos de desarrollo / Dinámicas económicas y conflicto armado / Economía y conflicto armado

- Despojo de tierras y desplazamiento forzado

- Narcotráfico y conflicto armado

- Resistencias, luchas sociales y transformaciones positivas

- Impactos sobre la integridad cultural y territorial de las comunidades 
○ étnicas

- Conflicto armado, sociedad y cultura

- Dimensiones internacionales del conflicto armado y exilio

- Actores armados y otros participantes en las dinámicas de la guerra

En el primer año de funcionamiento de la comisión, la dirección de conocimiento presenta el siguiente balance: 118 informes presentados, se han catalogado más de 3500 documentos, (publicaciones del Estado, sectores académicos y sociedad civil), 3805 entrevistas a víctimas testigos y familiares, de las cuales 190 se han realizado en Arauca, 9 diagnósticos comunitarios ( 1 en Arauca), 120 entrevistas colectivas (9 en Arauca), (13 Historias de Vida), 6 entrevistas a sujetos colectivos (2 en Arauca), 3 entrevistas a terceros civiles, 66 entrevistas a actores armados (5 en Arauca), en total, se han entrevistado 5951 personas.

Dirección de Diálogo social: cuyas funciones son, dirigir las coordinaciones de objetivos (convivencia, no repetición y reconocimiento), estrategias y enfoques; recoger y generar diálogo y reconocimiento. La dirección de Diálogo social busca poner en el país temas coyunturales para una discusión pública. Este año se centró en el asesinato de líderes y lideresas defensores y defensoras de derechos humanos. Se han realizado 6 encuentros en diferentes regiones, con invitados nacionales y regionales, son trasmitidos a través de la televisión pública y se busca que el país genere reflexiones para detener los procesos de violencia. En Arauca se realizó el segundo diálogo por la no repetición que fue trasmitido por Caracol Televisión; por otra parte, esta dirección de dialogo social viene promoviendo actos públicos de reconocimiento a la dignidad de las víctimas. Este años se han realizado cuatro encuentros: Víctimas de Violencia Sexual, Desaparición Forzada, Reclutamiento y Resistencia del campesinado. Arauca ha estado como territorio acompañante y participante de los reconocimientos de desaparición forzada y resistencia del campesinado, igualmente se están promoviendo en Arauca los mínimos humanitarios y los pactos de convivencia para tratar de des escalar el conflicto.

Dirección de Pueblos Étnicos: Para garantizar los derechos de los pueblos y comunidades étnicas y sus víctimas individual y colectivamente consideradas, y atender a sus necesidades diferenciales relacionadas con su contexto geográfico, lingüístico y diversidad cultural, la Comisión ha creado en el marco de su organización interna, un grupo de trabajo de 
enfoque étnico, el cual tendrá como función la coordinación y orientación del desarrollo metodológico y del despliegue territorial de la Comisión con pueblos y comunidades étnicas en articulación con los equipos de trabajo de la Comisión, en el marco de sus enfoques, estrategias, objetivos y oficinas territoriales. En el departamento de Arauca ya se realizaron trabajos con los 25 consejos comunitarios y las 19 organizaciones de baso de la población Afro descendiente; de igual manera, se ha realizado un trabajo de consulta previa con ASCATIDAR y ASOCATA que agrupan a los 26 resguardos de las comunidades indígenas presentes en el territorio.

En todo el proceso testimonial de la comisión, se han podido establecer una serie de responsables y responsabilidades en todos los territorios sobre lo ocurrido en el marco del conflicto, que serán consignados en el informe final. Sin embargo, por el carácter extrajudicial de la entidad esa información no podrá ser utilizada para hacer imputaciones penales, no tendrá valor probatorio, tampoco podrá ser trasladada por ésta a autoridades judiciales para ser utilizada con el fin de atribuir responsabilidades en procesos judiciales, ni las autoridades judiciales podrán requerírsela. La comisión tiene, por mandato de la Constitución, acceso a toda la información que necesite de las instituciones oficiales, incluso aquella reservada, siempre y cuando se garantice esa reserva. También debe tener acceso a los archivos de los grupos armados por fuera de la ley.

\section{Contraste normativo Procesos de Paz Caso: (AUC Y FARC).}

Entre ambos procesos existe un abismo grande en cuanto a la verdad se trata, dado que en la ley de justicia y paz no se contempla la creación de una comisión para la verdad, por ello, con el acuerdo de paz con las FARC, se destaca la creación de la primera comisión de la verdad en Colombia. Resulta ser la CVR una herramienta importante que ha apoyado a diferentes países con características similares de conflicto armado, por esto, tiene una serie de características que delimitan sus funciones dentro de este contexto: tiempo de operatividad, ¿como está conformada?, ¿cual es el objetivo de la aplicación de este mecanismo extra judicial? es decir, la información que surja en esta comisión no vincula jurídicamente a los actores, pues, por su naturaleza, obedece a un órgano investigativo que se vale de diferentes disciplinas académicas para realizar un análisis profundo del complejo problema social de conflicto armado que padece el pais colombiano 
En contraste, de cómo se conformó la CNNR y la CVR, se denota un gran avance, pues a diferencia de su antecesor, este tiene un alcance más profundo y centrado directamente en el derecho a la verdad, además, que tiene apoyo internacional para velar por el cumplimiento de este proceso, dentro de los cuales se observa: la Unión Europea, Unesco, PNUD, OCLAE, OEI que articula dichas instituciones y organizaciones, y que tienen la mision de hacer seguimiento del desarrollo del proceso, como en el financiamiento de los programas que allí se generan para la construcción de paz, los proyectos productivos de los desmovilizados, la recepción de testimonios, protección a testigos, diferentes beneficios encaminados a lograr la reincorporación de estos miembros a la sociedad colombiana, esto otorga mayores garantías a la hora de desarrollar tan aparatosa tarea

Otras características, que convienen señalar, es que en el proceso de las AUC se crea la (CNNR) Comisión nacional de reparación y reconciliacion; por otra parte, el proceso de paz con las FARC E.P se desarrolla el: "Sistema integral de Verdad, Justicia, Reparación y no Repetición" (SIVJRNR) dentro del cual está la CVR Comision de la verdad, algo que los diferencia es el tiempo de mandato de 3 años, dado que es muy corto para trabajar en un problema tan arraigado, esto puede ser una limitante, dado que se tiene que optar por reparar una situación que se ha desarrollado por más de 50 años.

Los miembros que conforman la CVR no son elegidos por el Presidente, a diferencia de la CNNR, pues da la potestad de que todos los sectores de la sociedad participen al poder postular candidatos de diferentes sectores que pueden ser elegidos como comisionados de paz dentro del proceso. En relación al producto final de la CVR, que es el informe final, lo sujeta a un posterior análisis y estudio por parte tanto de la sociedad colombiana, como los diferentes sectores internacionales implicados, en contraposición a la CNNR que solo recepciona la información que le quieran brindar los desmovilizados por medio de testimonios, sin lograr delimitar la raíz del problema, además que no se realiza un estudio posterior, acompañamiento, a las víctimas, ni a los resultados de las declaraciones.

Con la CVR no se crea una esperanza del fin de un conflicto que se ha perpetuado por años, su trabajo permite evidenciar cuáles fueron los patrones sistemáticos que causaron el conflicto y se posiciona como una forma de que el Estado participe, junto a los diferentes actores implicados en la solucion de la brecha social que ocasionó esta crisis de Estado. Se debe tener en cuenta la dificultad del mismo a la hora de garantizar sus postulados; 
al dar a conocer los hechos beligerantes, permite generar el repudio a estos actos de lesa humanidad, esto fomenta una Colombia diferente, promotora de los derechos humanos en la conciencia colectiva. Las diferencias de ambos procesos son plausibles, no solo en el sentido judicial, donde las penas fueron mucho más benevolentes con los reinsertados y no se logró generar una reparación concreta a multiplicidad de víctimas implicadas, si no en la concepción general de verdad y la inclusión de la población en este proceso que resulta importante al momento de fomentar la reparación del tejido social cercenado por el conflicto

\section{CONCLUSIONES.}

En cuanto a encontrar dónde se encuentra sumergido el contenido esencial del derecho a la verdad, tal como se ha se ha descrito con anterioridad, este reconocimiento como derecho y su importancia ha sido un proceso que ha tenido un avance progresivo, su génesis se determina en el derecho internacional reflejado en los Convenios de Ginebra del 1949, art. 32, que establece precedente sobre el derecho a la verdad, al reconocer la posibilidad de conocer la suerte de sus miembros, este aparte resulta principal en iniciar la disposición del derecho a la verdad, pues gracias a ello reconoció la necesidad de proteger a la familia de su derecho a conocer el paradero de sus familiares, de esta normativa se extracta que la verdad es fundamental, pues protege la posibilidad de, al menos, cerrar el duelo derivado de estos actos violentos

Por otro lado, el derecho a la verdad surge a través de la adscripción de los tratados internacionales ratificados por Colombia, que manifiestan su capacidad de actuar en razón al bloque de constitucionalidad, pues permite darle fuerza de ley a lo dispuesto por la Corte Interamericana de Derechos Humanos, como el Pacto de los derechos civiles y políticos en el año 1983, por causa del informe emitido por esos tratados internacionales que obliga a los Estados al deber de investigar, sancionar prácticas que atentan contra la vida de los ciudadanos y sus familiares. A partir de esta descripción se puede observar la evolución del derecho a la verdad, pues ya le otorga una amplia capacidad de acción, que incluye en términos generales cualquier afectación hacia la vida de una persona donde no tuviera decisión sobre ella, es decir, cuando los Estados no se encargan de proteger su orden jurídico y las regulaciones internas no son suficientes para tratar la problemática; esto es común en territorios donde es más intenso el conflicto armado, en tanto a estos contextos resulta natural que se realicen estas afectaciones, por 
ello, el derecho internacional protege a los seres humanos, como el orden social establecido que escasea en su función de proteger a sus pobladores, entonces se determina al contenido esencial del derecho a la verdad como parte de un todo, derivándose de la capacidad de convivir pacíficamente en una nación.

Pero su crecimiento no paró ahí, al contrario, se fortaleció gracias a la casuística que lo alimentó, es por ello que gracias a esto, hoy en día podemos consultar diferentes fallos donde, paso a paso, forman el esqueleto epistemológico para considerar a la verdad como un derecho, este derecho trae consigo cambios a la manera en que se concibe; inicialmente, se creía que obedecía solo a la persona afectada, luego le abrió lugar a los familiares como beneficiarios de el mismo y hoy en día es considerado en una triple dimensión, pues constituye al Estado como sujeto pasivo cuando se atenta contra sus pueblos, más aun si estos tienen el carácter de población sujeta a especial protección por parte del constituyente, si se toma en cuenta que Colombia posee una gran diversidad étnica y cultural, por lo cual, afectar estas poblaciones y el derecho a la verdad de ellos, es algo que puede ser considerado como afrenta hacia el patrimonio de la humanidad, como por referir algunos.

El contenido esencial del derecho a la verdad, no solo se adecúa a una población en específico, si no derechos conexos como la información, dignidad, vida, seguridad sersonal, democracia, y la legitimidad de las instituciones del Estado, puesto que si persisten las afectaciones, se escapa el control que debe ejercer el Estado y por el cual es el propósito de la creación del mismo, de esta manera se observa que cuando se trata el tema del derecho a la verdad, es de tal importancia, que si no logra protegerse ocasionaría la desestructuración del poder estatal, como se ha visto en el caso colombiano.

Cuando se afecta el derecho a la verdad es similar a quitar la tuerca de un complejo engranaje social que, a pesar de que el Estado tome medidas en reparar y darle carácter preventivo para que no se presenten más estas afectaciones, no satisface plenamente la necesidad de otorgar una reparación que también ha sido cobijada por la jurisprudencia internacional y las leyes estatales, pues si se afecta el orden normal de lo que se considera como el deber ser en un Estado y este no cumple su papel, debe la víctima obtener una forma de resarcir la situación que le produce sufrimiento, esta reparación no debe verse solo en materia de dinero, si no en crear una serie de prerrogativas orientadas a recuperar al afectado frente a sus costumbres 
sociales, pero con apoyos que permitan el crecimiento integral de la persona, como la protección de su dignidad personal. Esto lo vemos reflejado en la realización de diferentes formas de preservar la memoria histórica de los hechos victimizantes ocurridos, tales como homenajes, declaraciones, publicaciones, días donde el Estado recuerda los casos emblemáticos que hayan afectado directamente este derecho, para recuperar la legitimidad en las instituciones del Estado, y forjar la cultura de paz, motiva a la sociedad a evitar que se repitan estos actos beligerantes y además funciona para reparar los sectores que se han visto seriamente afectados por la guerra esto es lo que se atribuye en esencia al derecho a la verdad

Por ello, el camino que ha optado el país por seguir con los procesos de paz es el correcto, dado que los diferentes procesos de paz han ido evolucionando y la sociedad misma; basta ver la forma en que se concibe la verdad, los hechos victimizantes, el repudio que genera en las nuevas generaciones la utilización de la violencia como medio de poder, son formas de ver como se gesta el cambio. Sin embargo, es necesaria la articulación del Estado en estas políticas, es un deber garantizar la seguridad a los implicados en estos procesos, resulta de vital importancia para que no se sigan perpetuando las cadenas de odio, y el ciclo de la violencia vuelva a iniciar en un bucle de dolor y terror; Aún así, no puede desconocerse que algunos actores armados continúan delinquiendo y otros ya se apartaron de los acuerdos, de lo cual se resalta la aparición de nuevas células armadas, pero más que eso, la paz que se pretende debe continuar con quienes tienen esa firme convicción de alejarse de la guerra.

En este sentido, las garantías judiciales, sociales, integrales que permitan la reconstrucción del tejido social dañado, son herramientas importantes junto a la comisión de la verdad, y los procesos de paz son elementos que se adecuan a nuestro contexto particular, pero no basta con otorgarlas, si no en otorgarle mayor legitimidad, en aras de lograr una verdadera reconciliación que permita el avance general y el progreso, esto es lo que la verdad significa, además de ser el medio idóneo para lograr el anhelo de la paz en Colombia. 


\section{BIBLIOGRAFÍA.}

Bámaca Velásques, Serie C No 91 (CIDH 22 de Febrero de 2002).

BERNALES ROJAS, G.: "El derecho a la Verdad". En: Estudios Constitucionalesa, N², 2016.

Caballero, Delgado y Santana, Serie C No. 22 punto resolutvio 5 (CIDH 8 de Diciembre de 1995).

Caso Blake, Serie C No 36 (CIDH 24 de Enero de 1998).

Caso Vélazques Rodríguez, Serie C No 4, párr 181 (Corte Interamericana De Derechos Humanos 29 de julio de 1988).

CIDH: Derecho a la Verdad en las Ámericas . Washington D.C., 2014.

COMISIÓN COLOMBIANA DE JURISTAS: Anotaciones Sobre la ley de justicia y paz: una mirada desde los derechos de las victimas. Bogotá, Opciones Gráficas Editores Ltda., 2007.

Congreso De la República. (23 de Diciembre de 2002). Por medio de la cual se prorroga la vigencia de la Ley 418 de 1997, prorrogada y modificada por la Ley 548 de 1999 y se modifican algunas de sus disposiciones. Bogotá, Colombia .

Congreso de la República. (25 de Julio de 2005). Ley de Justicia y Paz. Bogotá.

Corte Constitucional. (8 de Mayo de 2006). Analisís justicia y paz. Bogotá, Colombia.

Corte Interamericana de Derechos Humanos, 1702,1748, 1755, Guatemala, Caso 1790,1874 Chile, caso 1798 Bolivia (Corte Interamericana de Derechos Humanos 1 de Junio de 1976).

Corte Interamericana de Derechos Humanos. (1986). Informe Anual de Derechos humanos.

Durand y Ugarte, Serie C, No 68 (CIDH 16 de Agosto de 2000).

GÓMEZ, J. D.: "Por los caminos de la memoria, La construcción social de la identidad de víctima." En: Kavilando, vol. 8, Nº1, 2016.

GÓMEZ, V. G.: "Derecho a la verdad: estudiantes desaparecidos en Ayotzinapa". México, 2015 (consulta: 11 de noviembre de 2019) 
GONZÁLEZ-SALZBERG, D. A.: "El derecho a la verdad en situaciones de post-conflicto bélico de carácter no-internacional". En: International Law: Revista Colombiana de Derecho Internacional, 2008.

Hermanos Paquiyauri, Hermanos Gómez Paquiyauri (CIDH 8 de JULIO de 2004).

COMISIONES DE LA VERDAD Y JUSTICIA PENAL EN CONTEXTOS DE TRANSICIÓN INDRET. En J. T. Sumalla. Barcelona, 2010.

MÁRQUEZ, G. G.: Cien años de Soledad. Buenos Aires: Plaza y Janes S.A., 1967.

Niños de la Calle, Serie C No 77 (CIDH 26 de MAYO de 2001).

ORGANIZACIÓN DE LAS NACIONES UNIDAS: El relator especial Theo Van Boven, proyecto de principios y diectrices básicos sobre el Derecho de las victimas de Violaciones Graves de los Derechos Humanos y el Derecho Internacional Humanitario a Obtener Reparacion. 1966. Consulta: 11 de septiembre de 2019

ORGANIZACIÓN DE LAS NACIONES UNIDAS: Conjunto de principios actualizado para la protección y la promoción de los derechos humanos mediante la lucha contra la impunidad. 2005. http://www.derechos.org/ nizkor/impu/impuppos.html

ORGANIZACIÓN DE LAS NACIONES UNIDAS: Asamblea General. (10 de 12 de 1948). Declaracion Universal de Derechos Humanos. Recuperado el 15 de 11 de 2019, de https://www.refworld.org.es/docid/47a080e32.htm

PINTO, M.: L'Amerique latine et le traitement des violations massives des droits de l'homme. Pedone, París, 2007.

Presidencia de la República. (5 de Abril de 2017). Se organiza la Comisión para el Esclarecimiento de la Verdad, la Convivencia. Bogotá, Colombia.

Radilla Pacheco vs Estados Unidos, Serie C No 209 (CIDH 23 de Noviembre de 2009).

RESTREPO, J.A.: "La etimología de verdad y la verdad de la etimología". En: Foro de Educación, vol. 3, №5-6, 2005.

SUMALLA, J. M.: "Comisiones de la verdad y justicia penal en contextos de transición.” En: DE GAMBOA, Camila (ed.) aIndret: Revista para el Análisis del Derecho, Nº1, 2010. 
VALLADOLID BUENO, (2005). Por una justicia postotalitaria. Antrhopos, Editorial del Hombre, Barcelona.

Xtemenes Lopes, Serie C no. 149 Parr 245 (CIDH 4 de Julio de 2006).

UPRIMNY, R. y SAFFON: "Derecho a la verdad alcances y limites de la verdad judicial”. EN: . Bogotá, 2006. 